\title{
Data Visualizations: Helping Students See Financial Accounting Concepts
}

\author{
Wayne Thomas \\ University of Oklahoma
}




\section{Data Analytics: Multi-level Approach}

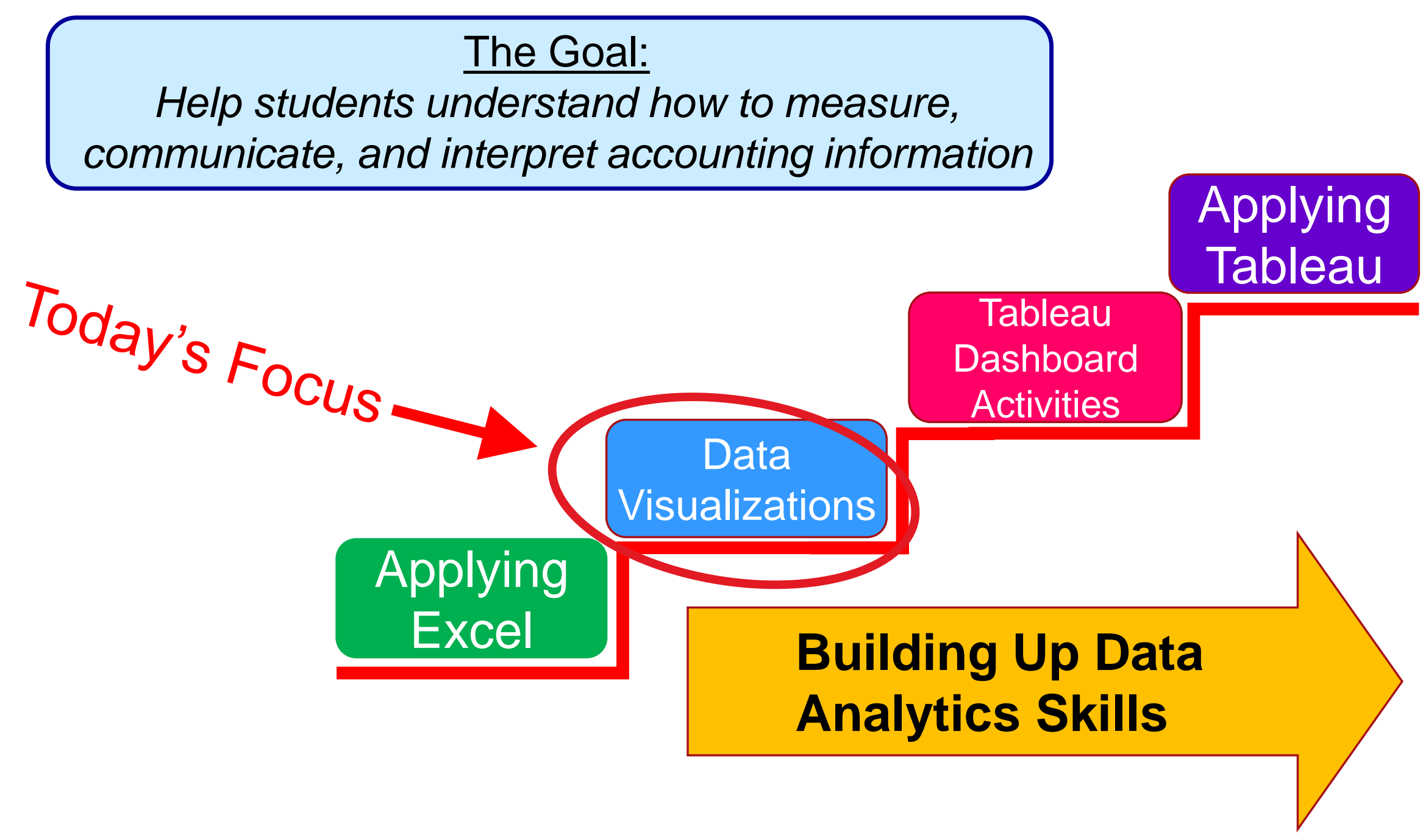




\section{Data Visualizations}

* Graphic representation of data

* Can we use visuals to help understand concepts?

* Topic: Balance of the Retained Earnings account

* Text description: "Cumulative amount of net income minus dividends over the life of the company."

* Numerical example in Illustration/Exercise:

\begin{tabular}{|lrrr|}
\hline & Year 1 & Year 2 & Year 3 \\
\cline { 2 - 4 } Net Income & 100 & 120 & 150 \\
Dividends & 20 & 30 & 40 \\
Retained Earnings & ?? & ?? & ?? \\
\hline
\end{tabular}

* Visual representation of the same concept? 


\section{Data Visualizations}

Net Income, Dividends, and Retained Earnings

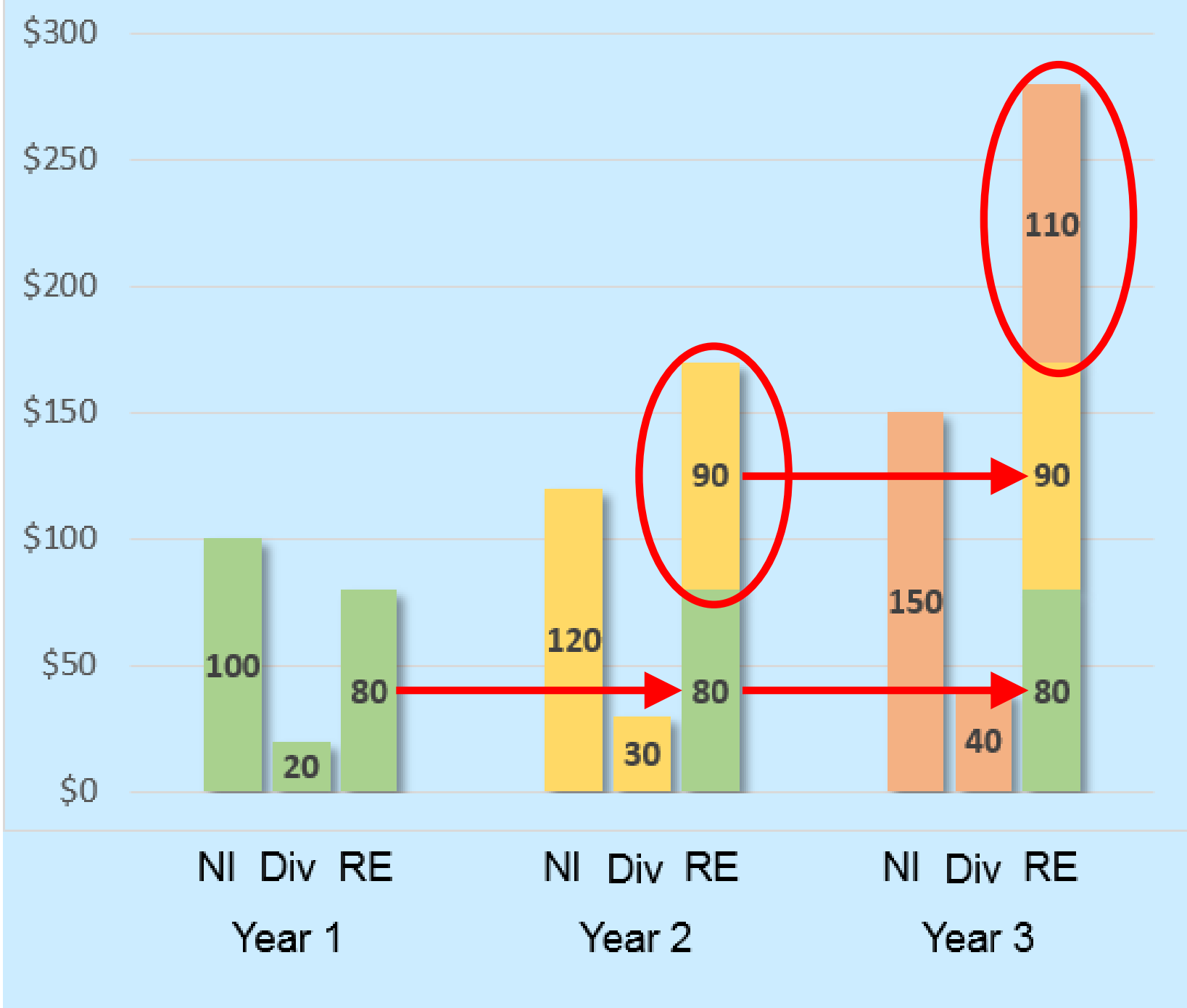




\section{Data Visualizations}

- What is the amount of Retained Earnings at the end of Year 1? \$80

- At the end of Year 2, the company reports Net Income of $\$ 120$. This amount includes: Revenues minus expenses in Year 2 only

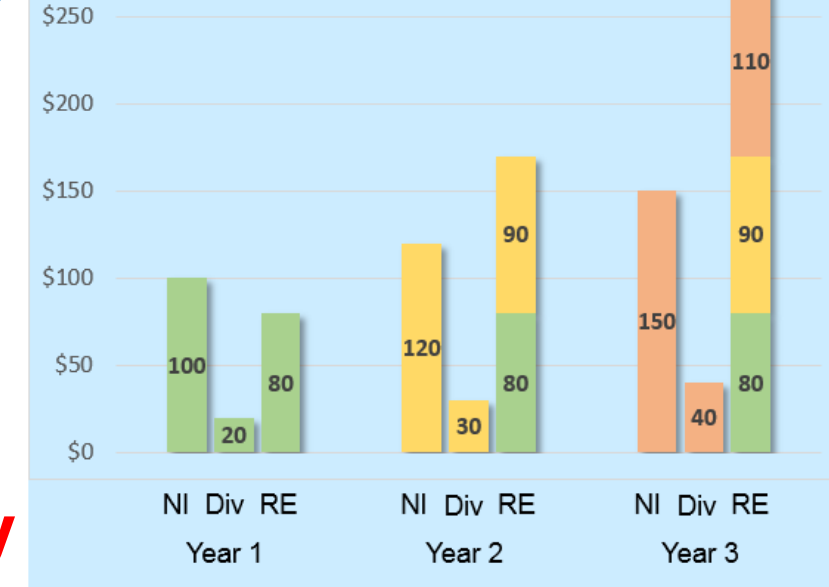

- What amount of dividends did the company declare in Year 2? \$30

- What is the ending balance of Retained Earnings in Year 2? \$170

- The ending balance of Retained Earnings in Year 2 includes: Net Income minus dividends from Year 1 and Year 2

- What amount of Net Income did the company report in Year 3? \$150

- What amount of dividends did the company declare in Year 3 ? \$40

- What is the ending balance of Retained Earnings in Year 3? \$280

- The ending balance of Retained Earnings in Year 3 includes: Net Income minus dividends from Year 1, Year 2, and Year 3 
Delivery Service Express (DSE) specializes in the delivery of refrigerated foods. The warehouse manager purchased a delivery truck for $\$ \mathbf{2 4 0 , 0 0 0}$. Part of the job of the Chief Financial Officer (CFO) is to depreciate the delivery truck over its estimated useful life. The CFO is considering three depreciation methods: activity-based, straight-line, and double-declining-balance.

The CFO has plotted depreciation each year (left graph) using an estimated five-year useful life. The right graph shows the accumulation of depreciation each year for each method.

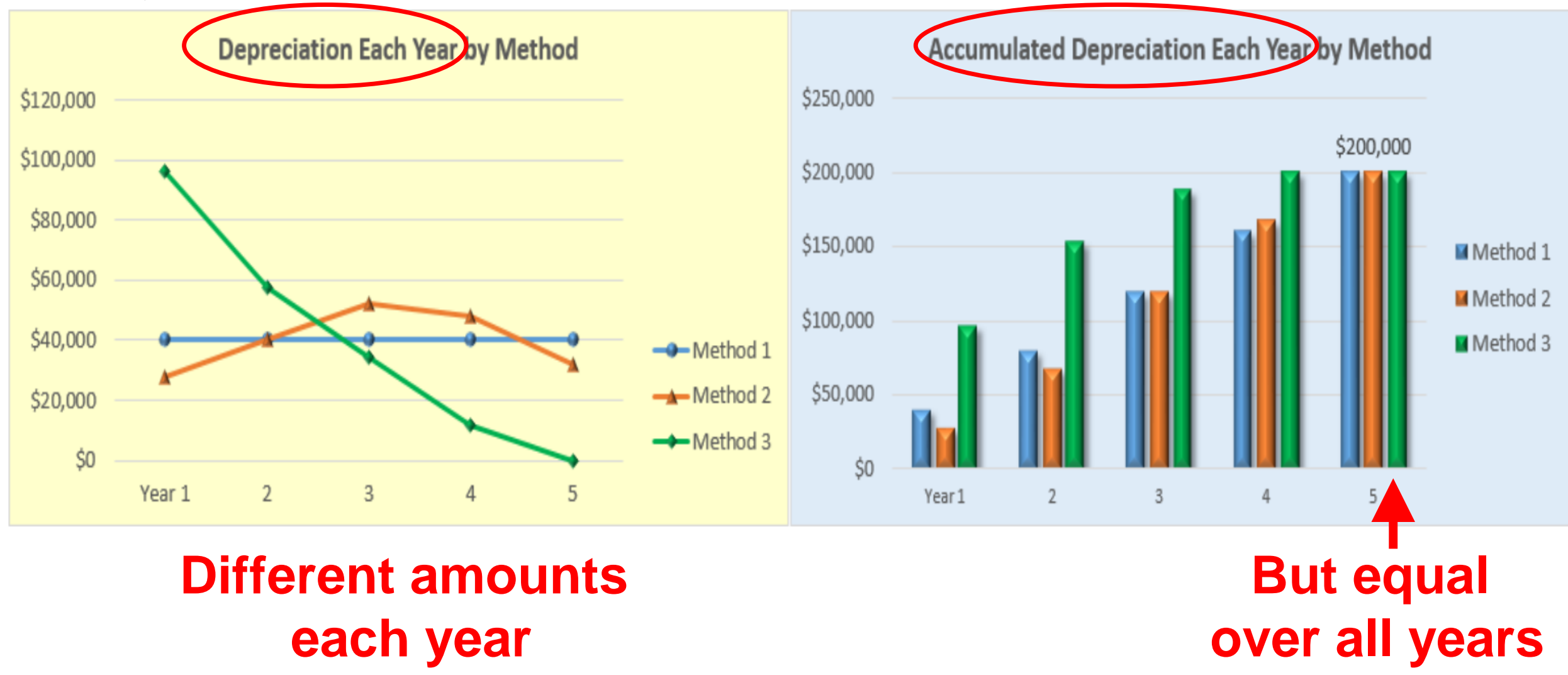




\section{Data Visualizations}

1. Which method is depicted by each option? SL, DDB, Activity

$2 \mathrm{~A}$. Which depreciation method results in the most depreciation in the first year of the truck's five-year useful life? Double-declining-balance

2B. Which depreciation method results in the same amount of depreciation each year? Straight-line

3. Which depreciation method results in the most accumulated depreciation by the end of the truck's five-year useful life? Same

4. What is the truck's estimated residual value (Hint: Recall the purchase cost of the truck is $\$ 240,000)$ ? $\$ 40,000$

$5 \mathrm{~A}$. By the end of Year 2, Accumulated Depreciation under Method 1 is $\$ 80,000$. What would be the reported book value of the truck at that time? $\$ 160,000$

5B. If the CFO instead uses Method 3, Accumulated Depreciation by the end of Year 2 would be $\$ 153,600$. What would be the reported book value of the truck at the end of Year 2 using Method $3 ? \mathbf{\$ 8 6 , 4 0 0}$ 


\section{Many Other Possibilities}

- Transaction effects on the accounting equation

- Revenues and expenses as components of retained earnings

- Bank reconciliation

- Bad debts

- Inventory ratios

- Lower of cost or market

- Deferred revenue

- Installment notes

- Shares outstanding

- Cash flows versus net income

- Assets versus liabilities in assessing risk

- Aggressive versus conservative accounting practices 


\title{
Thank You!
}

I hope you found something useful for your students.

Please feel free to reach out with further questions.

\author{
Wayne Thomas \\ wthomas@ou.edu
}




\section{Wayne Thomas}

\section{Brief Bio}

Senior Associate Dean for Faculty and Research Innovation

David C. Steed Chair in Accounting and

George Lynn Cross Research Professor

Michael F. Price College of Business, University of Oklahoma

Primary teaching includes:

$\checkmark$ Financial Accounting (275 students per section)

$\checkmark$ Intermediate Accounting (classroom \& online)

- He co-authors Financial Accounting 5e with David Spiceland and Don Herrmann. He also co-authors Intermediate Accounting 10e with David Spiceland and Mark Nelson.

- His research interests include accounting information in capital markets, techniques used by managers to manipulate earnings, the importance of financial disclosures, and financial statement analysis. He served as an editor for The Accounting Review and associate editor for Journal of International Accounting Research. 